\title{
Frequency of Post-Operative Wound Contamination in Bakhtawar General Hospital, Jamshoro
}

\author{
Altaf Hussain ${ }^{1}$, Ambreen Amna ${ }^{2}$, Saifullah Brohi ${ }^{3}$, Farkhunda Nadeem ${ }^{4}$, Amin Fahim $^{5}$, Muhammad Imran \\ Ahmed $^{6}$ \\ ${ }^{1}$ Assistant Professor, Department of Surgery, Mohammadi Medical College, Mirpurkhas \\ ${ }^{2}$ Associate Professor, Department of Obstetrics and Gynecology, Isra University Hospital, Hyderabad \\ ${ }^{3}$ General surgeon, Bakhtawar General Hospital and Trauma Center, Sehwan Shareef \\ ${ }^{4}$ Professor, Department of Pathology, Isra University, Hyderabad \\ ${ }^{5}$ Associate Professor, Department of Pathology, Isra University, Hyderabad \\ ${ }^{6} \mathrm{PhD}$ Fellow, Management Sciences, Shah Abdul Latif University, Khairpur
}

\begin{abstract}
A B S TRACT
Background: Surgical site wound infection (SSI) imposes a great challenge worldwide. It is the third most commonly reported nosocomial infection. The objective of the study was to assess the frequency of postoperative wound infections in a newly developed health organization.

Material and Methods: This cross-sectional study was conducted from June 2017 to May 2018 in Bakhtawar General Hospital, Jamshoro. A total of 364 cases of surgery, from Obstetrics and Gynecology and General Surgery department were included. Surgical interventions involving an incision were assessed. Infection (SSI) rate was noticed and data was analyzed by SPSS version 18.

Results: Healthy discharge rate was $97 \%$. The overall surgical site wound infection rate was $3.1 \%$. These infections were high in genitourinary surgeries (9.09\%). Among Obstetrics \& Gynecology surgeries, maximum number of SSIs were reported in cases of emergency Lower Segment Cesarean Section (LSCS).

Conclusions: The overall rate of SSI for different types of surgeries performed at Bakhtawar General Hospital, Jamshoro was only $3.1 \%$. Frequency of SSI was highest in genitourinary surgeries followed by gastrointestinal and obstetrics and gynecology surgeries, respectively.

Key words: General Surgery, Genitourinary surgery, Obstetrics \& Gynecology surgery, Post-operative wound contamination

Authors' Contribution: Correspondence:

${ }^{1}$ Conception; ${ }^{2-3}$ Literature research; Amin Fahim

manuscript design and drafting; ${ }^{4}$ Critical Email:draminfahim@gmail.com

analysis and manuscript review; Data

analysis; 5,6 Manuscript Editing.

Cite this article. Hussain A, Amna A, Brohi S, Nadeem F, Fahim A, Ahmed MI. Frequency of

Post-Operative Wound Contamination in Bakhtawar General Hospital, Jamshoro. J Islamabad

Med Dental Coll.2020; 9(1):54-58. Doi: 10.35787/jimdc.v9i1.294

Article info:

Received: March 1, 2019

Accepted: January 29, 2020

\section{Introduction}

Quality of health care is an important public health issue affecting the credibility of a newly-established hospital. Surgical site infections (SSIs) are wound infections that occur after invasive (surgical) procedures. ${ }^{1} \mathrm{SSI}$ are quite common and have been

estimated to occur in about $1.4 \%$ to $20 \%$ in surgical operations. ${ }^{2}$ They can lead to serious postoperative complications and consequences may affect both the patient and hospital. They represent one of the major causes of postoperative morbidity and
\end{abstract}


mortality along with increased length of hospitalization. ${ }^{3}$ It is reported that SSIs are the second most common form of nosocomial infections accounting for increased risk of death. ${ }^{4}$ The situation not only affect the reputation of the organization but may also lead to huge added health care cost, thereby increasing the clinical and economic burden of surgery. ${ }^{5}$

SSIs always have been an important factor in limiting the success of any major or minor surgery. They tend to occur at an undesirable rate despite constant efforts to improve the situation. ${ }^{6} \mathrm{~A}$ combination of risk factors are linked with SSI including patient age, obesity, anemia, diabetes, tobacco use, urinary incontinence, bad nutritional status, repeated surgery, complete neurologic deficit, use of NSAIDs, blood transfusion, prolonged surgical time, and the occurrence of more than three co-morbid illnesses. ${ }^{7}$

In Pakistan, like in any other developing country, surgical site wound infection rates are not documented and reported. Besides this, contributing factors mentioned above are very common in many hospitals. Keeping all these facts in mind, this hospital-based study was conducted to assess the frequency of postoperative wound infections in a newly developed health set-up (Bakhtawar General Hospital, Jamshoro).

\section{Material and Methods}

This cross-sectional study was performed at Bakhtawar General Hospital, Jamshoro, a secondary care level general hospital, from June 2017 to May 2018. It is a newly developed private organization situated in the heart of Jamshoro, Sindh. This hospital is providing health care facilities to upper Sindh and nearby villages of Jamshoro city. In the previous year, total number of outpatients were about 5345 and about 2234 surgical procedures were performed during this period. Major surgical procedures are defined as any invasive surgical approach for opening the body cavities for removal of an organ or any procedure resulting in alteration of normal anatomy. About 364 patients, who underwent major surgical procedures (both planned and emergency surgeries) were included through convenient sampling technique. Data was recruited from Departments of Obstetrics \& Gynecology and General Surgery including Gastrointestinal, Genitourinary, Hepatobiliary, Orthopedics, Breast and Others. Eye, ENT and Thyroid surgeries were included in "Others". All the minor surgical procedures, including traumarelated surgeries and major surgeries done on immunocompromised patients were excluded from the study. All the patients were assessed for status of wound postoperatively on eighth post-operative day according to the categorization criteria set by USA National Research Council as; Clean wound (Category-1), Clean and contaminated wound (Category-2), and Dirty and contaminated wound (Category 3). The information of patients was recorded and data analyzed by SPSS version 18 . Mean age of the participants along with frequency and percentages of categorical variables were calculated.

\section{Results}

The results of the present study revealed that out of total 364 major surgeries performed there were $267(73.3 \%)$ cases of Obstetrics and Gynecology surgeries while $97(26.4 \%)$ cases were of general surgery. The details of Obstetrics and Gynecology surgeries and General Surgery cases are presented in Table I and II, respectively. The mean age of the patients was $37+8$ years and majority of the patients (316; 86.8\%) were between 20 to 50 years of age while $39(10.7 \%)$ were above 50 years and 9 (2.47\%) of the patients were below 20 years, respectively. The overall SSI rate was $3.1 \%$ with highest rate reported in Genitourinary surgeries followed by Gastrointestinal and Obstetrics and Gynecology surgeries, respectively. 
Out of 07 patients of Obstetrics and Gynecology surgeries having SSI, 05 cases were operated for emergency LSCS and had dirty and contaminated wound while 01 case of laparotomy due to ovarian tumor and 01 case of vaginal hysterectomy had clean and contaminated wound, as shown in Table III.

\begin{tabular}{|l|c|}
\hline $\begin{array}{l}\text { Table I: Frequency of different types of Obstetrics and } \\
\text { Gynecology surgeries ( } \mathbf{n = 2 6 7 )}\end{array}$ \\
\hline Obstetrics and Gynecology surgeries & $\mathbf{n ( \% )}$ \\
\hline Elective Caesarean section & $118(52.2)$ \\
\hline Emergency Caesarean section & $108(47.8)$ \\
\hline Total number of Caesarean sections & $\mathbf{2 2 6}$ \\
\hline Total Abdominal Hysterectomy & $7(17)$ \\
\hline Evacuation & $24(58.5)$ \\
\hline Laparotomy & $04(9.7)$ \\
\hline Vaginal Hysterectomy & $04(9.7)$ \\
\hline Cervical Cerclage & $02(4.8)$ \\
\hline Total number of Gynecology surgeries & $\mathbf{4 1}$ \\
\hline Total & $\mathbf{2 6 7}$ \\
\hline
\end{tabular}

\begin{tabular}{|l|c|}
\hline \multicolumn{2}{|l|}{$\begin{array}{l}\text { Table II: Frequency of different types of General surgeries } \\
\text { ( } \mathbf{n}=97 \text { ) }\end{array}$} \\
\hline General surgeries & $\mathbf{n}(\%)$ \\
\hline Gastrointestinal & $28(28.9)$ \\
\hline Hepatobiliary & $22(22.7)$ \\
\hline Genitourinary & $33(34)$ \\
\hline Orthopedic & $3(3)$ \\
\hline Breast & $6(6.2)$ \\
\hline Others* & $5(5.1)$ \\
\hline Total & $\mathbf{9 7}$ \\
\hline
\end{tabular}

*Others included Eye, ENT and Thyroid surgeries

\section{Discussion}

Surveillance for SSI remains a great challenge, which is sometimes exacerbated by early discharge and outpatient surgeries. For better clinical and surgical outcome, it is recommended that surgical site wound infection should be diagnosed earlier and treated appropriately. Present study assessed status of postoperative wound following different types of surgeries performed at Bakhtawar General Hospital, Jamshoro, a secondary care level general hospital. The overall rate of SSI in the current study was $3.1 \%$. More or less similar results were obtained in other studies conducted in United States (SSI 2.8\%), Italy (SSI 2.7\%) and some European countries (SSI 2.5\%), respectively. ${ }^{8-10}$ On the other hand, surgical site infection rate as low as $1.0 \%$ has been reported by Degli et al in a study conducted in a children hospital. ${ }^{11}$ On the contrary higher rates of SSI have also been reported from different countries. A study from sub-Saharan Africa by Osakwe et al reported prevalence of surgical site infection as $15.5 \%,{ }^{12}$ while Yemen reported the rate of $\mathrm{SSI}$ as high as $34 \% .{ }^{13} \mathrm{~A}$ recent study carried out on surgical patients at Ayub Teaching Hospital in Abbottabad revealed a high SSI rate of $33.68 \%{ }^{7}$

Type of surgery seems to play a profound role in determining the development of SSI as reported by Nandita Pal in 2012. They reported $16.16 \%$ rate of SSI in open surgery as compared to SSI rate of $2.06 \%$ in minimally invasive surgery with multidrug resistant (MDR) bacteria and antimicrobial susceptibility pattern playing an important role. ${ }^{14}$ The present study shows higher SSI rate in genitourinary surgeries (3; 9.09\%). Among the gynecological surgeries, majority of the SSI cases belonged to the surgeries done in emergency. Similarly, in accordance with present study, another study showed SSI rates to be higher in emergency procedures (16\%) as compared to elective procedures (3\%). ${ }^{15}$

In present study, the follow up of postoperative patients specifically for the presence of infection

\begin{tabular}{|l|c|c|c|c|c|}
\hline Table III: Surgical intervention and the frequency of wound contamination & Slean and \\
\hline Type of Surgery (n; \%) & Clean & Dirty Contaminated & SSI Rate (\%) & Total \\
\hline Gastrointestinal $(28 ; 7.7)$ & 27 & - & 1 & 3.5 & 0 \\
\hline Hepatobiliary (22;6) & 22 & - & - & 9.09 & 28 \\
\hline Genitourinary (33;9) & 30 & - & 3 & 0 & 33 \\
\hline Orthopedics (3; 0.8) & 3 & - & - & 0 & 03 \\
\hline Breast (6; 1.6) & 6 & - & - & 2.62 & 06 \\
\hline Gynecology (267; 73.4) & 260 & 02 & 5 & 0 & 267 \\
\hline Others (5; 1.4) & 5 & & - & & 05 \\
\hline
\end{tabular}


was done on the eighth post-operative day. The dirty and contaminated wound found on follow-up might be due to substandard care at home. According to the results SSI rates were higher in gastrointestinal surgeries, which is similar to a study conducted at the Khyber Teaching Hospital, Peshawar by Khan et al who also reported high prevalence rate of SSI with gastrointestinal surgeries (13.51\%). ${ }^{16}$

\section{Conclusion}

The overall rate of SSI in the current study for different types of surgeries performed at Bakhtawar General Hospital, Jamshoro was only $3.1 \%$. Frequency of SSI was highest in genitourinary surgeries followed by gastrointestinal and obstetrics and gynecology surgeries, respectively.

\section{Recommendations}

Wound surveillance in the post-discharge period should be done by the primary surgeon, in order to rectify any surgical co-morbidity as well as for the correct estimation of SSI rate. Tri-monthly postoperative audit should be done in order to keep the SSI ratio up to bench-mark. Teaching and training of the surgical team regarding international surgical protocols should be done to achieve better health goals for all.

\section{Acknowledgment}

The authors are thankful to the administrator of Bakhtawar General Hospital, Mr. Barkat Ali Jatoi and Mr. Imran for their kind support throughout the study and statistical analysis. Hospital staff especially Mr. Sajid Ali Manager of Information Technology department also helped during collection of data.

\section{References}

1. Webster J, Osborne S. Preoperative bathing or showering with skin antiseptics to prevent surgical site infection. Cochrane Database Syst Rev. 2015; 20(2): CD004985. Doi: 10.1002/14651858.CD004985

2. Pawłowska I, Ziółkowski G, Wójkowska-Mach J, Bielecki T. Can surgical site infections be controlled through microbiological surveillance? A three-year laboratory-based surveillance at an Orthopedic unit, retrospective observatory study. Int Orthop. 2019; 43(9): 2009-16. Doi: 10.1007/s00264-019-04298-x

3. OHara LM, Thom KA, Preas MA. Update to the centers for disease control and prevention and the health care infection control practices advisory committee guideline for the prevention of Surgical site infection (2017): A summary, review and strategies for implementation. Am J Infect Control. 2018; 46(6): 602-9. Doi: 10.1016/j.ajic.2018.01.018

4. Khan HA, Baig FK, Mehboob R. Nosocomial infections: Epidemiology, prevention, control and surveillance. Asian Pac J Trop Biomed. 2017; 7(5): 478-82. Doi: 10.1016/j.apjtb.2017.01.019

5. Badia JM, Casey AL, Petrosillo N, Hudson PM, Mitchell SA, Crosby C. Impact of surgical site infection on healthcare costs and patient outcomes: a systematic review in six European countries. J Hosp Infect. 2017; 96(1): 1-15. Doi: 10.1016/j.jhin.2017.03.004

6. Elmously A, Gray KD, Michelassi F, Afaneh C, Kluger MD, Salemi A. Operating Room Attire Policy and Healthcare Cost: Favoring Evidence over Action for Prevention of Surgical Site Infections. ACS. 2019; 228(1): 98-106. Doi: 10.1016/j.jamcollsurg.2018.06.010

7. Sattar F, Sattar Z, Zaman M, Akbar S. Frequency of Post-operative Surgical Site Infections in a Tertiary Care Hospital in Abbottabad, Pakistan. Cureus. 2019; 11(3): e4243. Doi: 10.7759/cureus.4243

8. Nichols RL. Surveillance of the surgical wound. Infect Control Hosp Epidemiol. 1990; 11(10): 513-4.

9. National Nosocomial Infections Surveillance (NNIS) System report, data summary from January 1990May 1999, issued June 1999. Am J Infect Control 1999; 27: 520-32. Doi: 10.1016/s01966553(99)70031-3

10. Leaper DJ, Van Goor H, Reilly J, Petrosillo N, Geiss HK, Torres AJ, Berger A. Surgical site infection - a European perspective of incidence and economic burden. Int Wound J. 2004; 1(4): 247-73. Doi: 10.1111/j.1742-4801.2004.00067.x

11. Ciofi Degli Atti ML, Serino L, Piga S, Tozzi $A E$, Raponi $M$. Incidence of surgical site infections in children: active surveillance in an Italian academic children's hospital. Ann Ig. 201; 29(1): 46-53. Doi: 10.7416/ai.2017.2131.

12. Osakwe JO, Nnaji GA, Osakwe RC, Agu U, Chineke $\mathrm{HN}$ : Role of premorbid status and wound related 
factors in surgical site infection in a tertiary hospital in sub-Saharan Africa. Family Practice Reports. 2014; 1: 2. Doi: 10.7243/2056-5690-1-2

13. Nasser A, Zhang $X$, Yang L, Sawafta FJ, Salah B: Assessment of surgical site infections from signs \& symptoms of the wound and associated factors in public hospitals of Hodeidah City, Yemen. Int J Appl. 2013; 3(3): 101-10.

14. Pal ND, Guhathakurta. Surgical site infection in surgery ward at a tertiary care hospital: the infection rate and the bacteriological profile. IOSR J Pharm. 2012; 2(5): 1-5.
15. Khadilkar R, Khsirsagar V, Khadilkar S, Bendre M, Chavan S. A comprehensive study of 100 patients of SSI (Surgical Site Infections) in patients undergoing abdominal surgery, Elective/Emergency, in our Hospital. JMSCIR. 2017; 5(4): 20947-50. Doi: 10.18535/jmscr/v5i4.192

16. Khan $M$, Khalil J, Zarin M, Hassan TU, Ahmed N, Salman M, Muhammad G. Rate and risk factors for surgical site infection at a tertiary care facility in Peshawar, Pakistan. J Ayub Med Coll Abbottabad.

2011; 23(1): 15-8. PMID: 22830136 